Article

\title{
Experimental Flame Front Characterisation in a Lean Premix Burner Operating at Syngas
}

\author{
Edward Canepa ${ }^{1 *}$, Alessandro Nilberto ${ }^{2}$ \\ 1 DIME - Università di Genova, Via Montallegro 1, Genoa, I-16145 Italy \\ 2 DIME - Università di Genova, Via Montallegro 1, Genoa I-16145 Italy; a.nilberto@unige.it \\ * Correspondence: Edward.Canepa@unige.it; Tel.: +39-010-3532455
}

\begin{abstract}
The recent growing attention to energy saving and environmental protection issues has brought to attention the possibility of exploiting syngas from gasification of biomass and coal for the firing of industrial plants included the so called Integrated Gasification Combined Cycle ones. In order to acquire a detailed knowledge about the behaviour of lean turbulent premixed flames, the present work resent the results of an experimental characterisation of a prototypical gas turbine burner operated at atmospheric pressure at condition scaled from real gas turbines ones. The results here presented derive from OH-PLIF measurements carried out at decreasing air equivalence ratio conditions and are analysed together with a mean aerodynamic characterisation of the burner operating in isothermal condition. The $\mathrm{OH}$ concentration distributions have been analysed statistically in order to obtain information about the location of the most reactive zones and an algorithm has been applied to the data sets in order to identify the flame fronts. In addition, the flame front locations have been successively interpreted statistically in order to obtain information about their main features and about their dependence on the air to fuel ratio behaviour.
\end{abstract}

Keywords: gas turbine burner; syngas lean premixed flames; OH-PLIF; flame front detection.

\section{Introduction}

The attention to environmental protection and energy saving has increased in the last decades leading to more and more stringent regulations for power generation and transport emissions. Synthesis gas or "syngas" has shown to be a good opportunity to substitute, at least partially, fossil fuels in the near future. The syngas may be obtained through a large number of industrial activities such as the gasification of coal, biomass and organic waste, or through steam reforming of natural gas [1]. Basically, it is mainly composed of $\mathrm{H}_{2}$ and $\mathrm{CO}$ along with variable amount of $\mathrm{CH}_{4}$ and diluents like $\mathrm{N}_{2}, \mathrm{CO}_{2}$ and water vapour. The absence of particulate matter emissions and of corrosive elements in the ashes constitute a strong advantage if compared to conventional fuels as oils and coal. The differences in the adopted gasification technology or in the coal quality may lead to large variations in the syngas composition [2]. Such a variation may affects several parameters of the syngas combustion such as the flame speed [3-4], the ignition delay [5-6] and the extinction limit [7]. Consequently, the combustor design and operation may result largely complicated, especially in the case of gas turbine employ such as in the Integrated Gasification Combined Cycle (IGCC) power plants. In fact, most of the stationary gas turbine combustors are employing lean premixed combustion technology (LPC) which has been demonstrated to result in lower NOx emissions, if compared to standard diffusion flame. Unfortunately, such combustors are more susceptible to combustion instability and flashback [8]. When compared to natural gas, syngas is characterized by a higher laminar burning velocity and higher mass diffusivity, which may lead to different interactions between the flow turbulence and the reaction chemistry in turbulent premixed flame determining different flame characteristics in modern premixed-type combustors. Hence, due to the previously described increased interest, extensive studies of turbulent and premixed air/syngas combustion process are nowadays of great interest for the research community. Unfortunately, due to the properties of the $\mathrm{H} 2$-rich fuels, most of the studies about syngas combustion are operated with 
diffusion flames, e.g. [9-14], while in general a lower number of studies is present concerning lean premixed combustion experiments, e.g. [15-18]. Such a lack of data is evident for turbulent flame in real gas turbine geometries.

In such a scenario, the work here presented has been carried out by designing and manufacturing a prototypical swirl stabilized real scale like burner (500 kW power output in atmospheric operations) implementing the main current concepts of lean premixed combustors for gas turbine operations. The choice has been made of characterising the behaviour of the burner operated with a simplified model of $\mathrm{H}_{2}$ enriched syngas (supposed as it could be produced by coal gasification) at atmospheric pressure. As in lean premixed conditions, wide effects on flame shape, location and stability can be incepted by relatively constrained change in the air to fuel ratio, experimental measurements (Laser Doppler Velocimetry, Particle Image Velocimetry, Laser Induced Fluorescence) have been carried out for decreasing air equivalence ratios and statistically analysed, also in the light of the aerodynamic features of the motion flow field generated within the combustion chamber by the burner.

\section{Experimental facility and measurement technique}

\subsection{The test-rig}

The experimental results here presented have been obtained exploiting the experimental facilities present at the Savona Combustion Laboratory of the Mechanical Engineering Faculty, University of Genoa.

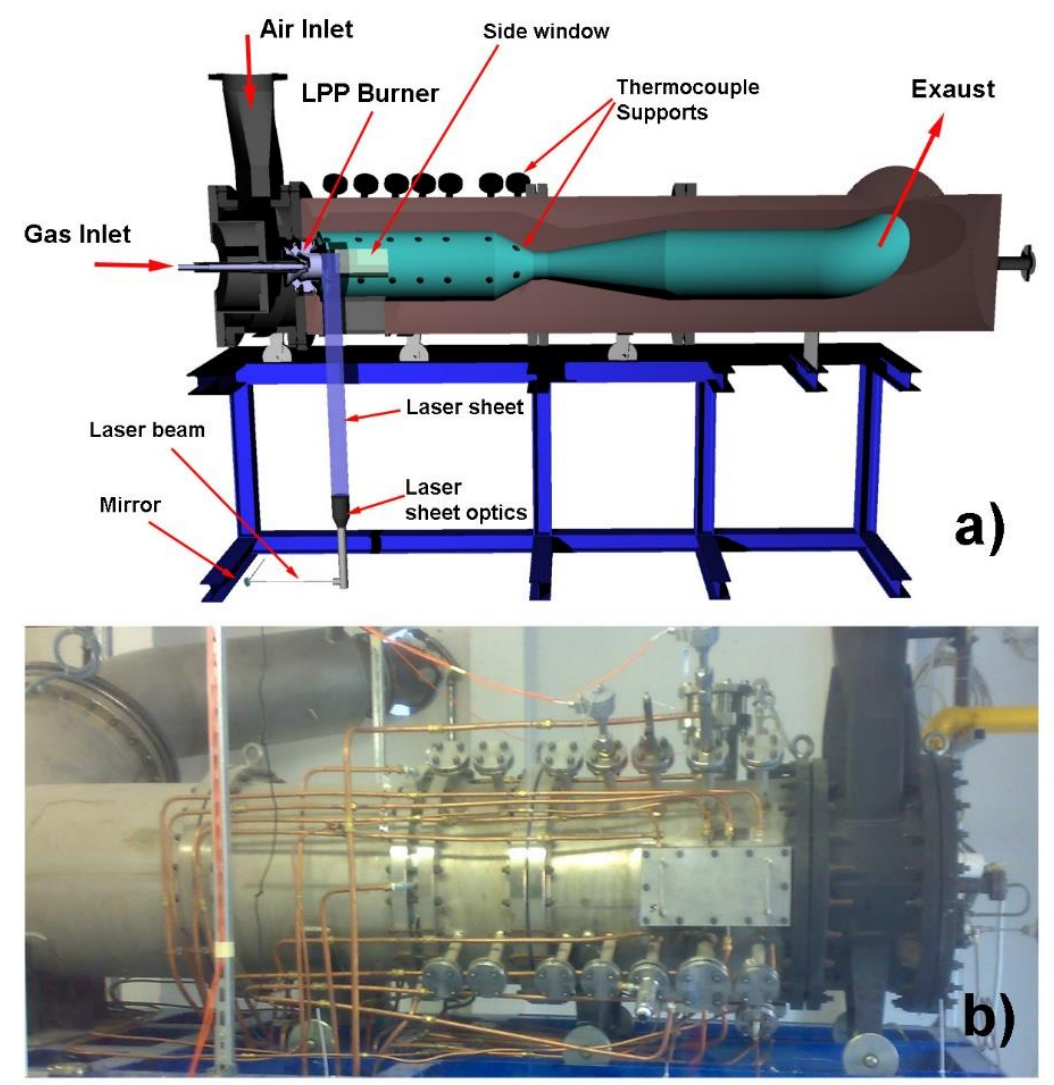

Figure 1. Burner test-rig: a) a section of the rig seen from the right side, b) picture of the rig seen from the left side where the settling chamber (black section at left end), the test section equipped with physical accesses and optical windows (blinded in the picture) can be seen.

Since 2010, a test-rig aimed at the in-flame investigations of combustion phenomena has been settled at Savona Campus of Genoa University (Figure $1 \mathrm{a}$ and b). The rig can reach a firing power 
up to $500 \mathrm{kWth}$ in atmospheric operations and up to $2.5 \mathrm{MWth}$ in pressure ( $5 \mathrm{bar}$ ), where the mass flow rate of combustion air equals $2900 \mathrm{~kg} / \mathrm{h}$ and it is preheated up to $500^{\circ} \mathrm{C}$. Such a test rig is equipped with a combustion chamber/test section completely thermally insulated by a multiple-layer refractory and equipped with optical accesses on three sides (right, left and bottom sides: in order to ensure an adequate view and to perform laser based in-flame diagnostics) and physical accesses for intrusive measurement probes (thermocouples, pressure transducer, pyrometers, etc.).

The test section is characterized by a variable geometry with the possibility of modifying its length by the insertion or removal of a $317 \mathrm{~mm}$ long cylindrical section, depending on the test operating conditions. Furthermore, the combustion chamber has, downstream the test section strictly considered, a convergent segment driving the flow through a constricted cross-section, realized by means of the insertion of a steel septum, aimed at generating a pressure loss simulating the presence of the gas turbine first stage.

As previously mentioned, in order to allow in depth investigations of the combustive processes taking place within the combustion chamber by means of laser based non-intrusive measurement techniques, the test section has been provided with properly designed optical accesses. Three $200 \mathrm{~mm}$ X $80 \mathrm{~mm}$ quartz glass windows are placed on three sides (right side, left side and bottom side) of the chamber just downstream the burner outlet.

In order to support the possibility of feeding multi-fuel burners equipped with multiple injection systems, the rig has been provided with four independent fuel lines fully instrumented with all the measurement and monitoring instrumentations and retroacted control devices. The fuel lines can be both connected to the natural gas network and to alternative fuel sources (i.e. syngas or special gas mixtures tanks).

\subsection{The burner prototype}

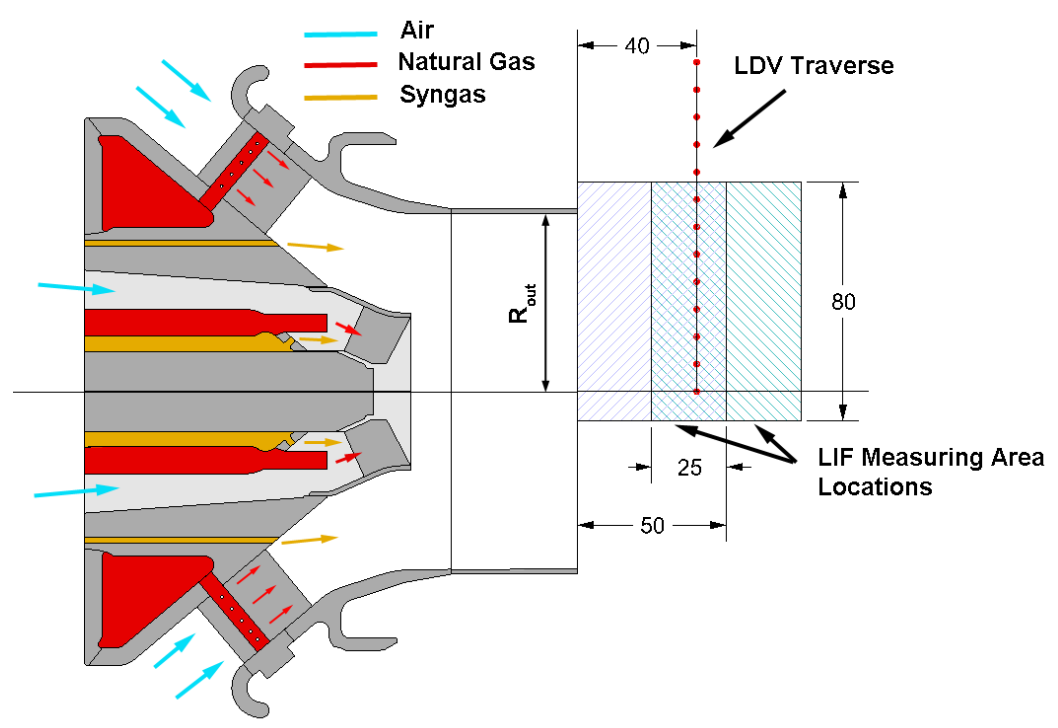

Figure 2. Sketch of the burner indicating the flow paths for air and fuels and the LIF measurement locations as well as the LDV one; all the quotes are expressed in $\mathrm{mm}$.

Within the frame of the present study, a swirl stabilized burner prototype (Figure 2), with a nominal thermal power output (atmospheric pressure operations) of $500 \mathrm{~kW}$, has been utilized. It is equipped with two swirlers: an axial inner one, whose air mass flow rate is about the $15 \%$ of the total one, and a centripetal outer swirler elaborating the remaining part (85\%) of the air mass flow rate.

The burner can be fed with both natural gas (NG) and $\mathrm{H}_{2}$ enriched syngas (SG) by means of dedicated injection systems. The fuel nozzles are located slightly upstream of the inner axial swirler which provides a diffusive flame aimed at the overall combustion stabilization. Differently, in the centripetal swirler, the fuel nozzles are placed along the vanes (NG operations) or immediately downstream (SG operations) and such a flow generates the main premixed flame. 
A cylindrical duct (whose radius is $R_{o u t}=59 \mathrm{~mm}$ ) is placed downstream of the swirler assembly and collects the incoming flows before the combustion chamber inlet. A sketch of the burner is depicted in Figure 2 showing the airflow paths and the fuel nozzles locations.

The experimental investigations reported in the present work have been carried out in the combustor near field (close to the cylindrical duct outlet section) within the combustion chamber.

\section{3. $L D V$, PIV and LIF diagnostic systems}

In order to characterize the flow field in the burner outlet region, the isothermal $\left(350^{\circ} \mathrm{C}\right)$ nonreactive velocity distribution has been investigated by means of a Laser Doppler Velocimetry and a Particle Image Velocimetry measuring campaigns. The LDV instrumentation is composed by a $300 \mathrm{~mW}$ argon ion laser light source, operating at $514.5 \mathrm{~nm}$ (green) and $488 \mathrm{~nm}$ (blue). The transmitting probe has a front lens of $400 \mathrm{~mm}$ focal length and a beam separation of $38 \mathrm{~mm}$, resulting in a geometrical control volume of $90 \mu \mathrm{m}$ diameter and $1.9 \mathrm{~mm}$ length.

The probe is stiffly mounted on a three-axis computer-controlled traversing mechanism. The motion is transmitted to the carriages by stepping motors through a preloaded ball-screw assembly with a minimum linear translation step of $8 \mu \mathrm{m}$. A Bragg cell is used to apply a frequency shift $(40 \mathrm{MHz})$ to one of each pair of beams and allows to solve directional ambiguity and to reduce angle bias. The flow has been seeded with a 0.5-2.5 $\mu \mathrm{m}$ atomized spray of silicon oil injected in the settling chamber. The Doppler signals are transmitted by optical fibres to the receiving unit (Dantec Dual PDA 58N81 detector unit) where they are filtered to minimize the background noise. The signal transduced by the photomultipliers is collected by a Burst Spectrum Analyzer (Dantec BSA P70 processor). The frequency range extends from $122 \mathrm{~Hz}$ up to $120 \mathrm{MHz}$, with accuracy better than $0.1 \%$ of the bandwidth. Dedicated software is used for the data post-processing. The measurements have been performed on a radial traverse located $40 \mathrm{~mm}$ downstream of the burner discharge section (Figure 2) with a radial extension equal to nearly twice the burner outlet radius $R_{\text {out }}$. A $5 \mathrm{~mm}$ radial step has been adopted. For each measuring point, 100000 velocity samples have been collected. Since a statistical bias can occur because the arrival times of the measurable particles are not statistically independent on the flow velocity, which brings them into the probe volume to compute correctly the average values, the data have been weighted with the residence time of the particles in measuring volume. For the present experiment, the uncertainty of the instantaneous velocity was evaluated to be less than $1 \%$. ([19], [20]).

The PIV instrumentation is composed by a double-cavity Nd:Yag pulsed laser (energy $2 \times 400 \mathrm{~mJ}$ per pulse at $532 \mathrm{~nm}$, pulse duration $8 \mathrm{~ns}$, repetition rate $10 \mathrm{~Hz}$ ). The two beams are combined and form a light sheet with a thickness of $2 \mathrm{~mm}$ which enters the combustion chamber from the bottom window and is focused in vertical meridional plane (Figure $1 \mathrm{a}$ ). The light scattered by the seeding particles has been recorded on a Dantec High Sense MkII digital camera with a CCD matrix of 1344 $x 1024$ pixels. The camera maximum frame rate in the double frame mode is $6 \mathrm{~Hz}$, and the minimum interframe interval is $200 \mathrm{~ns}$. The investigated area (not indicated in Figure 2 for sake of brevity) has an extension of 1.9 Rout in the axial direction and of $2.6 R_{\text {out }}$ in the radial one, and is centred with respect of the burner axis. A total amount of 3000 couples of images has been acquired. Once the PIV images have been captured and digitized the velocity field has been obtained using a spatial cross-correlation function calculated over $64 \times 64$ pixels, $50 \%$ overlapped, interrogation areas. The experimental uncertainty for the instantaneous velocity is estimated to be $4 \%$, according to the PIV error analyses of Grant et al. [21] and Prasad et al. [22]. After cross-correlation operation, data were post processed to remove outliers, applying range scale validation and peak validation.

The LIF measurement system exploits a laser source, to excite the OH Q1(6) line in the $\mathrm{A}^{2} \Sigma-\mathrm{X}^{2} \Pi$ $(1,0)$ band, consisting of a diode pumped Nd:YAG laser (Quantel Brilliant B) capable of generating a pulsed (repetition rate up to $10 \mathrm{~Hz}$ ) beam @ $1064 \mathrm{~nm}$ wavelength with $850 \mathrm{~mJ}$ energy and, being equipped with a temperature stabilized second-harmonic generator, a second beam @ $532 \mathrm{~nm}$ wavelength with $400 \mathrm{~mJ}$ energy. The laser pump works in combination with a Tuneable Dye Laser utilizing, for the here presented experimental activity, a solution of Rhodamine 590 in ethanol. The 
output UV beam is driven throughout a screened optical path to ordinary UV-coated sheet forming optics to form the light sheet $50 \mathrm{~mm}$ high illuminating the combustor region of interest.

The excited $\mathrm{OH}$ radicals were imaged onto an image intensified (Hamamatsu Image Intensifier Unit C-9546) camera (Dantec Hisense Mk II), with a full resolution of $1344 \times 1024$ pixels and a quantum efficiency above $70 \%$ within the wavelength range $450-550 \mathrm{~nm}$. The camera allows the pixel binning in $2 \times 2$ and $4 \times 4$ modality, in order to increase both sensitiveness and frame rate. The signal digitalisation is performed on a 12-bit basis in both single frame and double frame mode.

The synchronization of laser, camera and image intensifier of the LIF system have been controlled from the DynamicStudio (Dantec) software platform via an 8-channell high-resolution (250 ps) synchronizer unit. The synchronizer unit is also equipped with two additional input channel, supporting the measurements synchronization with external triggering signals.

The measurements have been carried out in two axial locations (Figure 2), where the first is located as close as possible to the burner outlet section and the second is shifted axially downstream of $25 \mathrm{~mm}$. The overall investigated area, after the sampled image post processing, has an extension of $1.09 R_{\text {out }}$ in the axial direction and of $1.3 R_{\text {out }}$ in the radial one.

\section{Results}

\subsection{Air flow field characterisation}

The flow field generated by the burner has been investigated in isothermal non-reactive conditions representative of the nominal power output working point. Hence, the adopted mass flow rate is the same of such an operating condition $(0.426 \mathrm{~kg} / \mathrm{s} @ 500 \mathrm{~kW})$. The air has been preheated at $350^{\circ} \mathrm{C}$. The flow field referred to unreactive conditions, even if characterised by the same values of air mass flow rate and preheating temperature, cannot be uncritically assumed as stringently representative of the reactive aerodynamics in the combustion chamber. Nevertheless, the main flow features and the order of magnitude the aerodynamic phenomena should be reasonably preserved when moving to the reactive conditions ([23]). For such a reason, in the present case the unreactive flow characteristics will be described as deemed useful in order to interpret the OH-PLIF results.

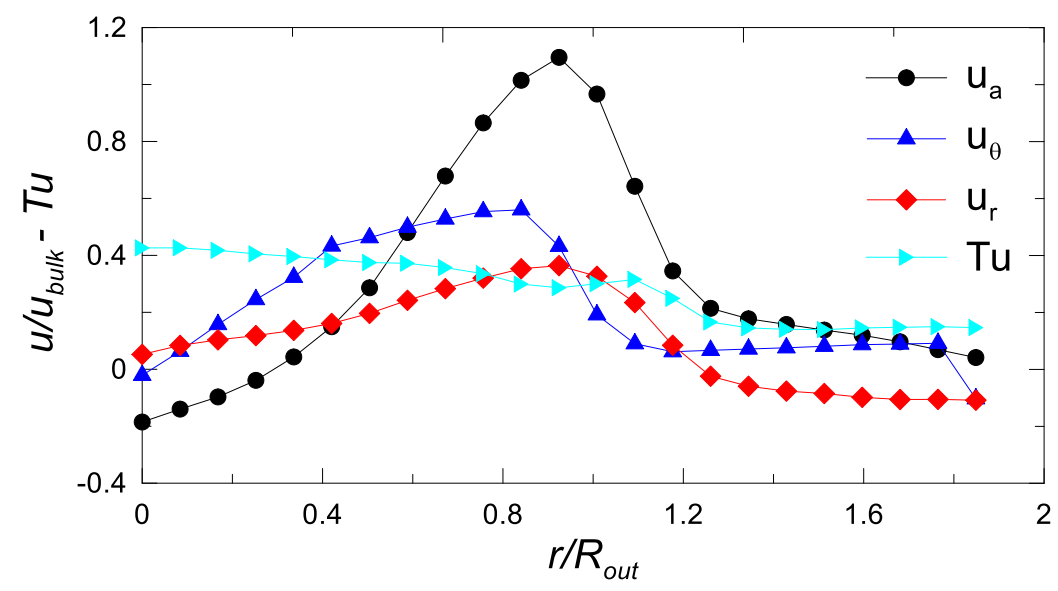

Figure 3. Radial distributions (traverse at $\mathrm{x} / \mathrm{d}=0.34$ ) of axial, radial and tangential velocity components.

The radial profiles of the three mean velocity components $u_{a}, u_{r}$ and $u_{q}$ (axial, radial and tangential velocity components respectively) made non-dimensional with the bulk velocity $u b u k$, measured at $x / R_{\text {out }}=0.67$ where $x$ represents the axial direction, are reported in Figure 3 . The $u b u l k$ velocity has been obtained according to the following equation:

$$
u_{\text {bulk }}=m /\left(\rho \pi R_{\text {out }}{ }^{2}\right)
$$

where $\mathrm{m}$ represents the air mass flow rate. 
A zone characterized by negative axial velocity can be observed ranging from the duct centreline to $\mathrm{r} /$ Rout $=0.29$. For larger radii such a component increases to a maximum equal to $1.1 \mathrm{ubulk}$ located at $\mathrm{r} /$ Rout $=0.92$ from which it decreases with a rapid decay to an outer zone characterized by values close to 0.1 ubulk. The axial component profile, hence, indicates the presence of an Inner Recirculation Zone (IRZ), typical in swirl-stabilized injectors ([24], [25], [26], [27], [28], [29]), having, in the selected axial position, a radial extension corresponding to $29 \%$ of the burner outlet diameter. Similarly, the flow leaving the burner is concentrated in an annular jet, which shows a centrifugal behaviour as suggested by the ur profile characterized by continuously positive values (the maximum value is equal to 0.36 ubulk at $r /$ Rout $=0.92$ ). The uq profile indicates that the tangential velocity component behaves like a Rankine vortex with free vortex distribution in the external region and solid body rotation near the jet centreline. The flow turbulence has been evaluated according to the following equation:

$$
T u=\sqrt{\left(\overline{u_{a}^{\prime 2}}+\overline{u_{\theta}^{\prime 2}}+\overline{u_{r}^{\prime 2}}\right) / 2} / u_{b u l k}
$$

where random fluctuation $u^{\prime}$ is obtained considering the instantaneous velocity $u$ in a generic position as the sum of the mean velocity plus its random fluctuation: $u=\bar{u}+u^{\prime}$. For sake of simplicity, in the legend of Figure 3 and in the rest of the paper, the overbar indicating the mean value has been omitted.

The $T u$ profile indicates that in the IRZ and in the annular the turbulence level is particularly high, with values in the interval $0.30 u_{b u l k} \div 0.4 u_{b u l k}$ and with a local maximum $(0.32$ ubulk $)$ placed at $r / R_{\text {out }}=1.09$, which is probably the shear layer of the outer part of the jet.
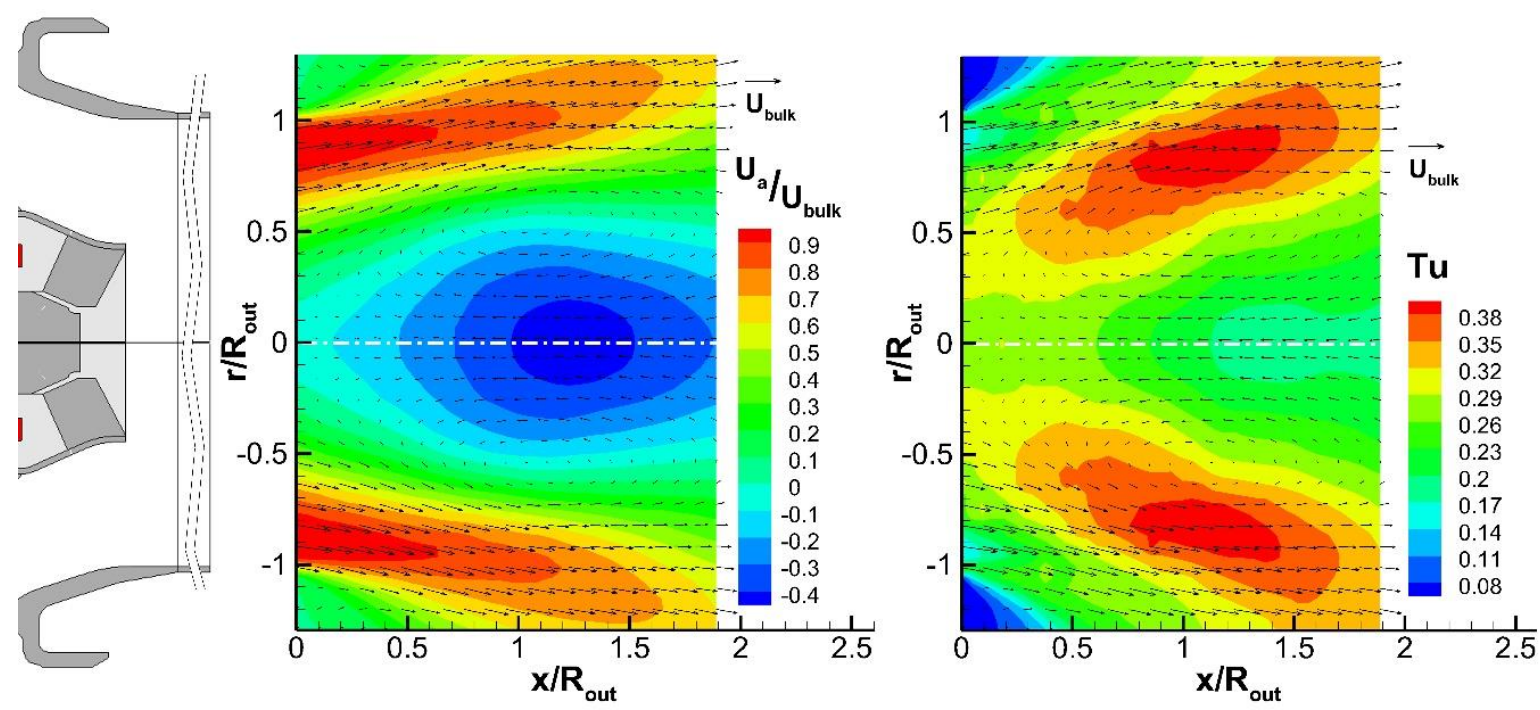

Figure 4. PIV measurements in a meridional plane: contour plots of the axial velocity component (left) and of the turbulence intensity (right) with superposed the velocity vector field.

In order to provide a more immediate representation of the flow field in a meridional plane, a PIV measuring campaign has been performed and the results are reported in Figure 4 as contour plots of the axial velocity component and of $T u$, with the vector field superposed. The turbulence intensity, which is represented, has been obtained neglecting the part related to tangential component since it cannot be measured by such a technique. The distribution of $u_{a}$ confirms that the flow is concentrated in an annular jet confined by two recirculation zones. Close to the burner outlet section the jet shows large positive values which gradually decrease with axial coordinate increase. Moving downstream, the jet diverges and the cross section becomes larger. At the same time, due to turbulent mixing, the distribution tends to attenuate non-uniformities. Close to the burner outlet at large radii, a trace of the corner recirculation may be seen, while across the duct axis the IRZ recirculation zone, associated to the large tangential momentum and the sudden jet expansion in the combustion 
chamber, appears evident. The maximum negative values of $u_{a}$ is around 0.4 ubulk located in the region $1<r / R_{\text {out }}<1.5$. The superimposed vector plot provides an immediate representation of the meridional mean flow field suggesting that the ring like jet may be separated into two regions: an upstream one characterized by the reverse flow leaving the IRZ, and a downstream area where the flow enters the separation bubble (i.e. the IRZ) moving from outer diameter towards the duct axis. The Tu distribution indicates that the largest random fluctuations of the axial and radial components are located at the interface between the annular jet and the internal separated flow.

Even if such a flow field analysis simply based on time-averaged values cannot reveal the actual dynamic interaction between the IRZ and the surrounding high velocity region, anyway it is able to provide with the basic characteristics, which may be useful for the following analysis of the experimental characterisation of the combustion process, object of the present work.

\subsection{OH-PLIF measurement}

Combustion tests have been carried out in operating conditions corresponding to the working point chosen as reference condition for the flow field characterisation. So that, the same air mass flow rate and preheating temperature have been utilized $\left(0.426 \mathrm{~kg} / \mathrm{s} @ 350^{\circ} \mathrm{C}\right)$.

The tests have been carried out in ultra-lean, partially premixed flame conditions, with the aim of exploring the effects on flame positioning, shape and spatial stability due to air to fuel ratio modification in those that could reasonably be possible gas turbine conditions.

In particular, attention has been dedicated to operations of the experimental burner with a hydrogen rich syngas model. The syngas composition have been chosen to be $85 \% \mathrm{H}_{2}$ and $15 \% \mathrm{~N}_{2}$ by volume (respectively, $29 \% \mathrm{H}_{2}$ and $71 \% \mathrm{~N}_{2}$ by mass).

The results here presented refer to three different values of the air equivalence ratio $(\lambda)$ at constant air mass flow rate (i.e. at variable thermal power output).

Testing conditions are summarized in the following Table 1:

Tab. 1: burner test conditions

\begin{tabular}{|c|c|c|c|c|}
\cline { 2 - 5 } \multicolumn{1}{c|}{} & $\begin{array}{c}\text { Air mass flow } \\
\text { rate }[\mathbf{k g} / \mathbf{s}]\end{array}$ & $\begin{array}{c}\text { Ait temperature } \\
{\left[{ }^{\circ} \mathbf{C}\right]}\end{array}$ & $\boldsymbol{\lambda}$ & $\begin{array}{c}\text { Thermal power } \\
\text { output [kW] }\end{array}$ \\
\hline Operating condition \#1 & 0.426 & 350 & 3.60 & 411 \\
\hline Operating condition \# 2 & 0.426 & 350 & 3.25 & 456 \\
\hline Operating condition \# 3 & 0.426 & 350 & 2.90 & 500 \\
\hline
\end{tabular}

All tests have been carried out addressing the $16 \%$ of total fuel mass flow rate to the nozzles feeding the central stabilizing, pilot, diffusive flame.

In order to characterise the flame and its position, shape and spatial stability, the OH-PLIF diagnostic technique has been exploited.

According to many classical sources in scientific literature ([30]-[34]), theoretical calculation on laminar premixed flames provide information about the determination of molecules that can be possibly exploited as tracer for the flame front position determination. Generally, three molecules, $\mathrm{OH}, \mathrm{CH}$ and $\mathrm{CH}_{2} \mathrm{O}$, are the most frequently used in premixed turbulent flame experimental characterisations.

Independently of how good tracers of flame fronts could be recognised to be $\mathrm{CH}$ and formaldehyde (and both show limiting shortcomings, i.e. quite low concentrations the $\mathrm{CH}$ and possible significant formation of $\mathrm{CH}_{2} \mathrm{O}$ quite before the actual flame front), they are not exploitable in the present case due to no carbon kinetic involved in the combustion of utilized fuel.

On the other hand, the concentration of $\mathrm{OH}$ radical is relatively high in premixed flames (both hydrocarbon/air flames and hydrogen/air flames) and, additionally, its concentration increases rapidly in the reaction zone. This rapid increase can be exploited in experimental approaches to mark the beginning of the flame front. The disadvantage of $\mathrm{OH}$ is that it is widely spread in the "postflame" region, so that mere concentration maps of $\mathrm{OH}$ cannot be directly adopted for locating flame 
fronts. However, this limitation can be handled by adopting a proper flame front detection method, as it will be described in the following.

Moreover, the utilization of laser-based techniques (LIF) for the $\mathrm{OH}$ in flame detection are well studied and accounted ([15], [35]-[44]). Thence, all the results that will be presented in the following will refer to OH-PLIF measurements. The raw images processing has been utilized in order to obtain information about shape, position and spatial fluctuation of the flame fronts.

Six hundreds OH-PLIF raw images has been collected for each operating condition, in order to reduce the statistical uncertainty in the data. Such a number of samples was found to be a good trade-off between a sufficiently high number of samples and a reasonable data acquisition and post-processing time. The adopted procedure to post process the acquired images is indicated in Figure 5 and will be hereby explained.

Sets of 40 background images were collected without a flame, but with the laser running, in order to take into account as background noise both the radiation coming from the combustion chamber walls and the scattered laser light. One set of 20 images has been acquired before the measurement run corresponding to each of the operating conditions and 20 further at its conclusion. Averaging the two sets gave the average background for each acquisition session. This average background image was used to correct the raw images.

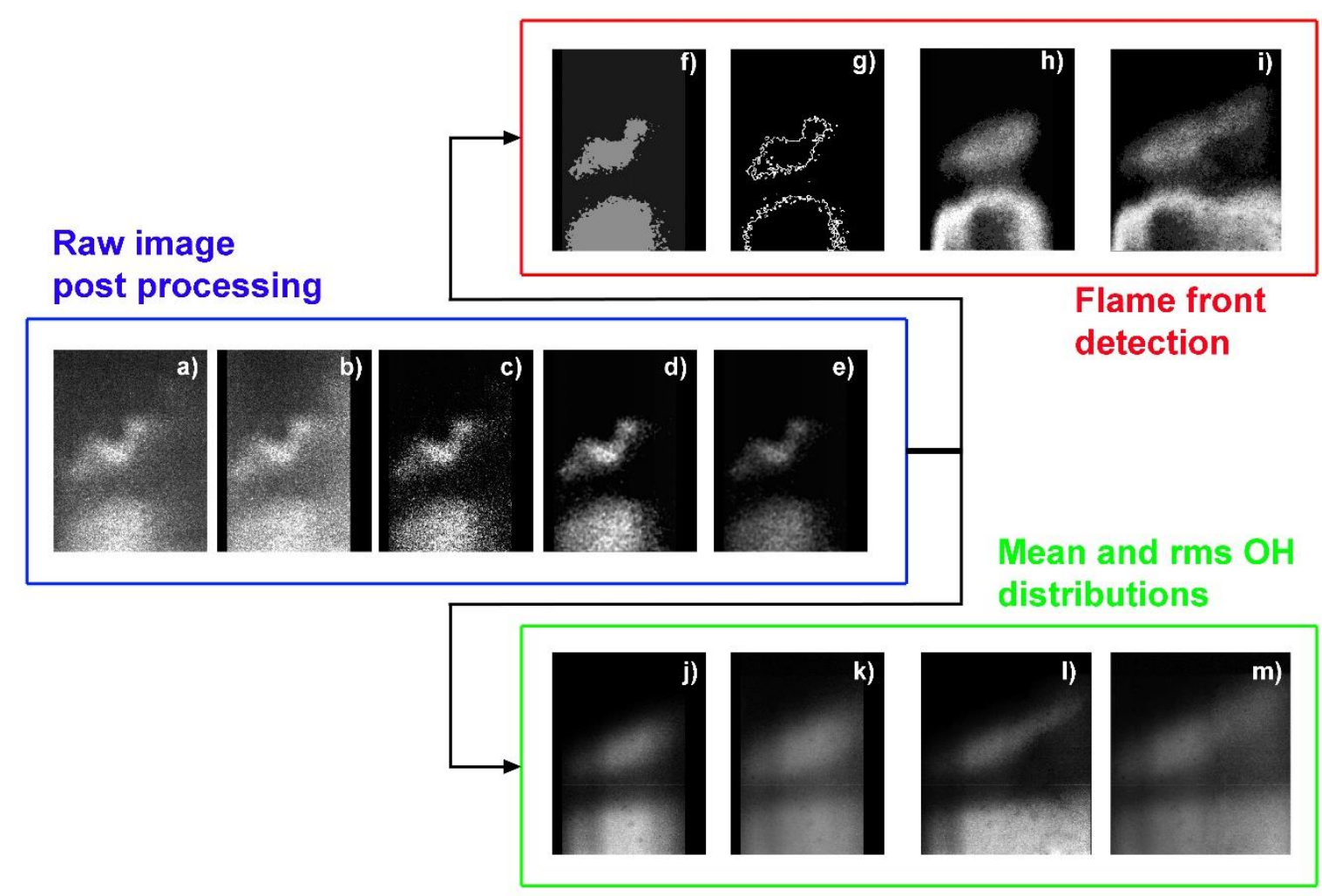

Figure 5. Raw OH-PLIF image processing steps: a) raw image; b) image balancing and masking; c) background subtraction; d) median (9 X 9) filter application; e) filtering by intensity histogram rescaling; f) NLD filter application; g) Sobel gradient detector application; h) averaging of 600 flame fronts; i) joining of the flame front averages from the two LIF investigation areas; j) averaging of 600 $\mathrm{OH}$ concentration maps (images from step e); k) RMS of $600 \mathrm{OH}$ concentration maps (images from step e); 1) joining of the $\mathrm{OH}$ concentration maps averages from the two LIF investigation areas; $\mathrm{m}$ ) joining of the $\mathrm{OH}$ concentration maps RMS from the two LIF investigation areas.

In order to account the axial unevenness of the laser sheet (due to possible misalignments or not perfect neatness of optics within the tuneable dye laser or along the optical path to the test section), a properly designed target has been adopted to collect a set of images which allow to identify the mean laser sheet footprint, which results in the real axial distribution of light. Therefore, it has been 
possible to determine a correction function, which has been applied to each raw image to take in account such an unevenness. Since the axial extension of the collected images has been set larger than the laser sheet, such a function has been used also to black out the not illuminated areas (or not enough illuminated). The effects of this two-step post processing is shown in Figure $5 \mathrm{a}, \mathrm{b}$ and $\mathrm{c}$.

Subsequent filtering was required to reduce the noise content of the original OH PLIF image, which in turn improved the accuracy of subsequent flame-front detection. Smoothing of images by reducing the high-frequency pixilation noise was obtained by applying a $9 \times 9$ median filter (Figure 5 d). Furthermore, to remove potentially spurious intensity fluctuations of the laser beam, the collected images have been filtered by analysing the intensity histogram and equalizing the max-min range in order to allow a correct and uniform use of the greyscale dynamic range $(0 \div 255$ basis for an 8 bit signal). The effect of such a post processing is depicted in Figure $5 \mathrm{e}$. The so conditioned and balanced images has been used to perform a statistical analysis of the data, obtaining the average distribution of $\mathrm{OH}$ and the rms one (Figure $5 \mathrm{j}$ and $\mathrm{k}$ ). Successively, the averaged and rms distributions obtained from the two measurement locations have been joined as shown in Figure 51 and $\mathrm{m}$.

In order to extract the flame front from the conditioned and balanced images, a further postprocessing algorithm based on the detection of the $\mathrm{OH}$ signal intensity gradient in the reaction zone has been applied. In fact, a combination of median (already used in the step shown in Figure $5 \mathrm{~d}$ ) and non-linear diffusion (NLD) filters has been used to condition the OH-PLIF images. The NLD filter requires a threshold value, which has been derived by the statistical treatment of the intensity histograms. According to [38] and [45], thresholds are set in a neighbourhood of the $15 \%$ of the maximum intensity of the mean distribution of each images set.

Hence, the application of the NLD filter ([46], [47]) leads to a "remove outliers" effect (Figure $5 \mathrm{f}$ ), where regions of the selected image, characterized by values larger than the threshold, are smoothed to a uniform value. Differently, no smoothing occurs between or across the boundary of such regions. This kind of application of the NLD filter is well accounted as a powerful tool in flame front detection process as reported in [48] (concerning diffusive flames), [49] (in a two stroke internal combustion engine case) and ([41] (for lean partially premixed flames).

By using median and NLD filters, the flame-front edges are preserved and their position not artificially shifted. Furthermore, the pre-process by means of a median filter improves the quality of the NLD filter, reducing the noise content and so lowering the number of erroneous flame fronts identified by the later processing.

Finally, the flame front detection has been performed applying a Sobel gradient detector (Figure $5 \mathrm{~g}$ ), allowing by this the separation of the image processing procedure from the edge detection operation. Among other gradient operators, the Sobel one represents a good choice as it has a simple implementation and, furthermore, by adopting a central differencing scheme on a $3 \times 3$ pixel matrix, it only considers pixel intensity in a close neighbourhood ([50]).

Successively, the single image flame fronts have been processed with a simple statistical analysis obtaining the average distribution of the flame fronts (Figure $5 \mathrm{~h}$ ). Similarly, to the $\mathrm{OH}$ distributions, the average flame front distributions obtained from the two measurement locations have been joined, as shown in Figure 5 i.

\section{Discussion}

The contour plots of the mean distributions of the $\mathrm{OH}$ radical, as well as the rms, are reported in Figures 6 and 7, where the three selected operating conditions are depicted from left to right for $\lambda=3.60,3.25$ and 2.90 respectively (thus, from left to right side $\lambda$ decreases). Moreover, to improve the figures clarity, a sketch of the burner have been added (the burner cylindrical outlet has been shortened in the picture for editing reasons). The spatial scale of the sketch and of the contour plots have been kept equal and the duct axis location is preserved, consequently this layout should be helpful in improving the correct location of the general features of the reacting areas. 

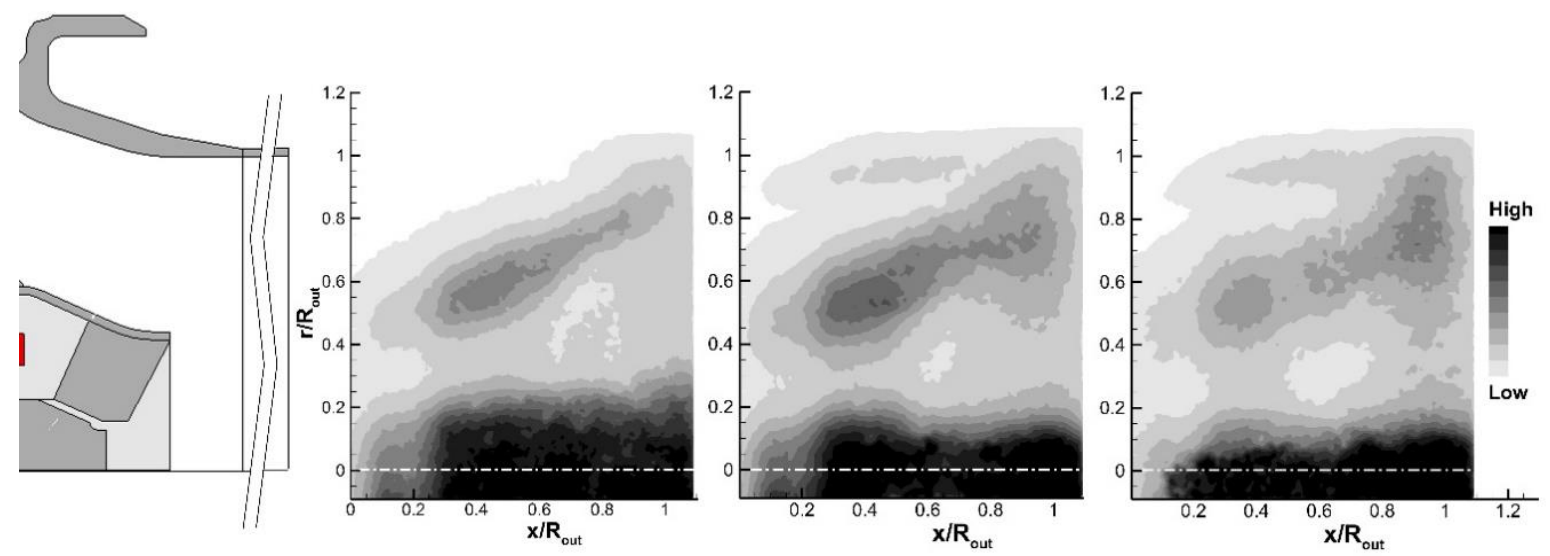

Figure 6. PLIF measurements: average $\mathrm{OH}$ concentration maps for (from left side to right side) operating conditions from $\# 1$ to $\# 3(\lambda=3.60,3.25$ and 2.90 respectively).

For all the working points, the reaction zones show some common features. An intense reaction zone confined within the portion of meridional plane close to the duct axis where the IRZ is present. Besides, a second intense reaction region is located in across the shear layer between the IRZ and the surrounding annular jet, although it is characterized by $\mathrm{OH}$ concentration values lower than the previous one. This two main reaction zones show a complementary behaviour as $\lambda$ decreases. In fact, the reaction region placed within the IRZ appears to be progressively thinned in radial direction for enriched combustion conditions, whilst the one located on the inner shear layer strengthens (i.e. the $\mathrm{OH}$ concentration increases) and widens for reduced air equivalence ratios. Such an effect is stronger at large value of $x / R_{\text {out }}$. Furthermore, at $\lambda=3.25$ and 2.90 a third reaction area may be detected and is located on the external shear layer (i.e. between the annular jet and the outer surrounding flow). The resulting scenario indicates that the reduction of the equivalence ratio determines a general broadening in radial direction of the reaction area placed on the inner shear layer and the emerging of a new area located on the outer one.

The analysis of the contour plots of the rms of the $\mathrm{OH}$ concentrations, depicted in Figure 7 , indicates that the largest fluctuations are located in the reaction zone close to the duct axis and particularly in its downstream part. In fact, for $\lambda=3.60$ the largest fluctuations extend in an area whose axial range is $0.9<x / R_{\text {out }}<1.1$. For $\lambda=3.25$ such an area results axially increased and in the range $0.75<x / R_{\text {out }}<1.1$. Finally for $\lambda=2.90$ large value fluctuations may be detected already at $x / R_{\text {out }}=0.4$. A similar effect, even if less evident, is present also in the reaction zone located across the inner shear layer. Anyway, the general trend of the rms contour plots suggest that the $\mathrm{OH}$ concentration fluctuations become higher as the equivalence ratio is reduced.
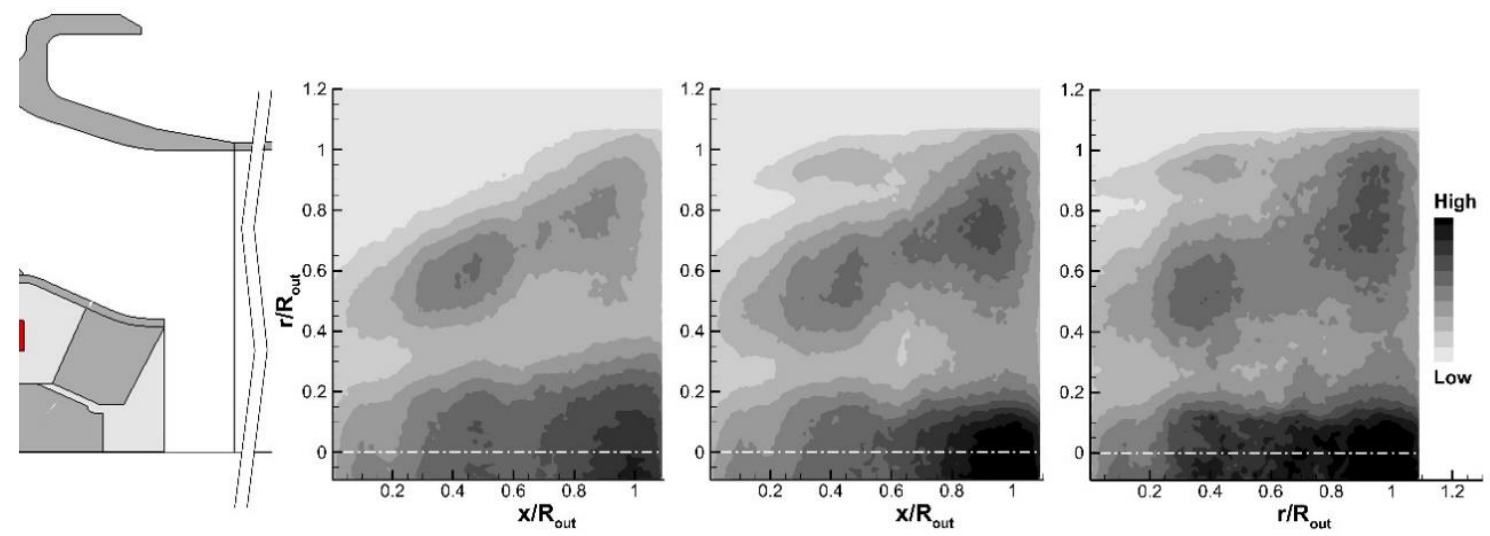

Figure 7. PLIF measurements: RMS of $\mathrm{OH}$ concentration maps for (from left side to right side) operating conditions from $\# 1$ to $\# 3$ ( $\lambda=3.60,3.25$ and 2.90 respectively). 
It is well known that the $\mathrm{OH}$ concentration contours can provide information on the location of the chemical activity as well as on the temperature field, but they cannot be exploited in their standard form for the flame front identification.

For this reason, the previously described algorithm for the flame front identification has been applied to the OH_PLIF images. This resulted in a set of 600 instantaneous flame fronts for each of the investigated locations and operating conditions. Three instantaneous flame fronts referred to each of the operating condition here discussed (from left to right, $\lambda=3.60,3.25$ and 2.90 respectively) are depicted as an example of flame front detection in Figure 8.
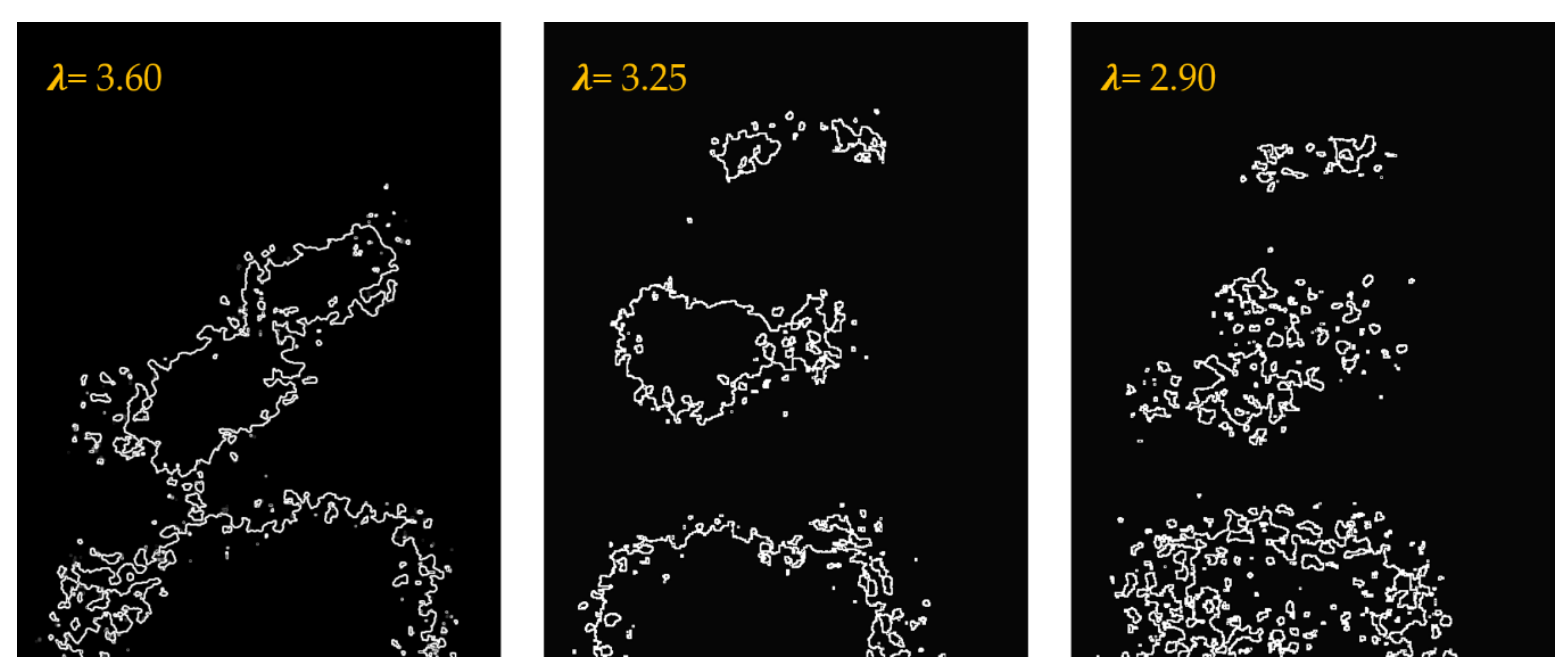

Figure 8. Typical instantaneous flame fronts for the three operating conditions (flow direction from left to right).

In all the three operating conditions, the individuated flame fronts appear uniformly corrugated along the entire frontiers, being assignable to the corrugated flamelets region in the Borghi/Peters diagram (reported for sake of completeness in Figure 9) and showing, for decreasing $\lambda$, the activation of flame fronts of limited extension also in correspondence of the external shear layer. Such behaviour (corrugated flamelets along all frontiers) is compatible with high reactivity and diffusivity of hydrogen, even in significantly fuel lean conditions.

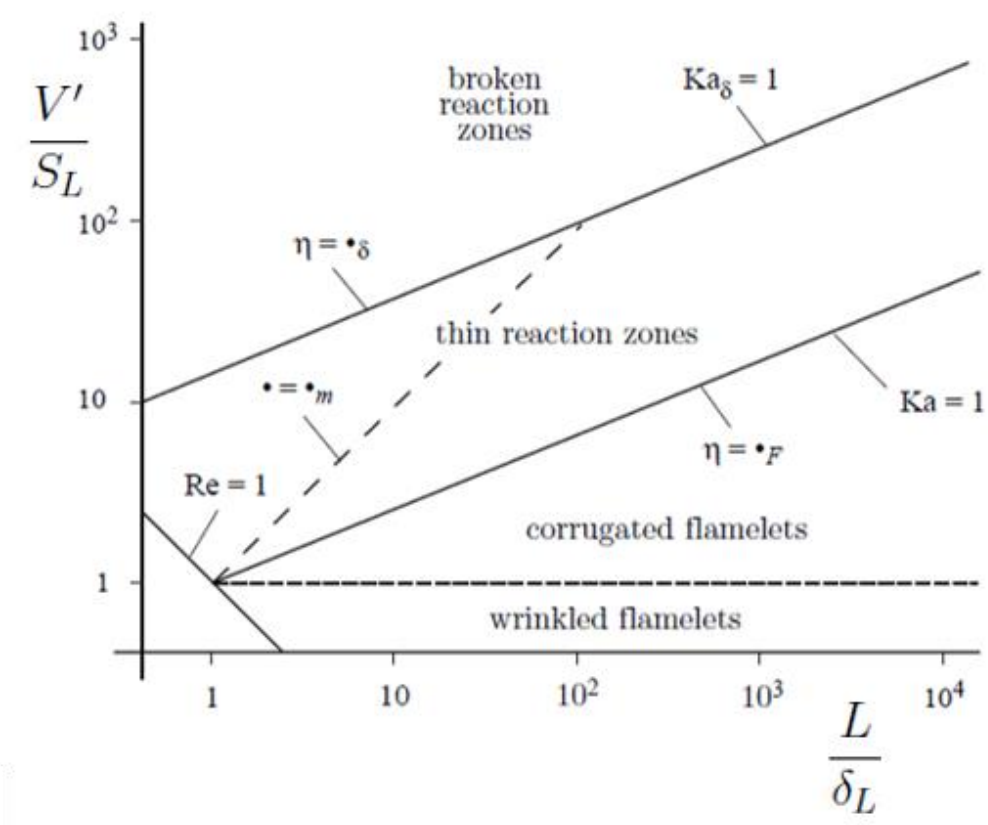

Figure 9. Borghi/Peters diagram. 
Looking at the flame structures for the different burner loads, corresponding to the different air equivalence ratios, some observation can be done about the mutual interaction between turbulence and flame fronts. Considering the blow-up (Figure 10) of a portion, as an example, of the $\lambda=3.60$ single shot flame front previously shown (consider that at a local and small scale level, also the other flame fronts, at different air equivalence ratios, appear behaving similarly), it can be noticed that at local and small-scale level the flame front appears not as convoluted and thickened as, in analogous thermal fluid-dynamics conditions, natural gas flames could appear.

The high local propagation velocity, as implied by hydrogen combustion, induces an increase of the turbulence characteristic scale able of producing the flame front circumvolution. In accordance to the Gibson criterion, the turbulence length-scales effective in corrugating the flame front have characteristic dimensional scales increased in reason of increased reactivity and propagation velocity.

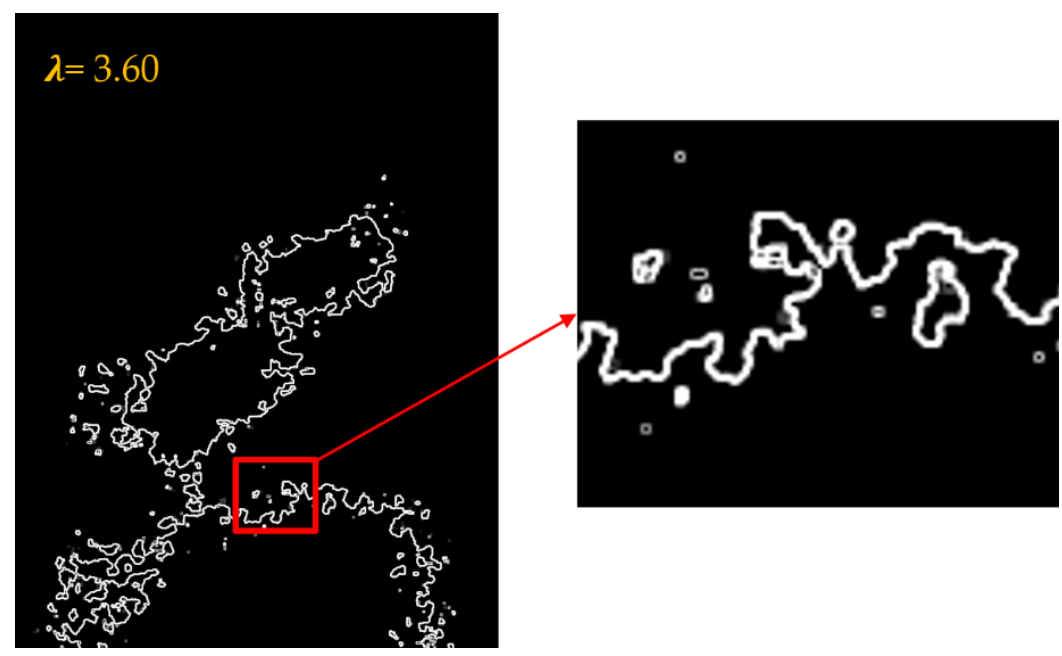

Figure 10. Corrugated flame front for operating point $\# 1$ - detail of local small-scale behaviour.

Furthermore, a higher flame temperature produces a more intense action of flow "laminarization" inhibiting the effect of the smallest turbulence scales in thickening the flame front. These two actions, above described, lead to the not so corrugated and thickened flame front observed, even in the case of a self-evident corrugated flamelet, as the one here considered.

As reported in Figure $5 \mathrm{j}$, for each operating condition the flame front locations of each measuring area have been averaged and joined. The results are depicted in Figure 11 and represented as contour plots where the three selected operating conditions are depicted from left to right for $\lambda=3.60,3.25$ and 2.90 respectively (thus, from left to right side $\lambda$ decreases). It can be observed that the average siting of the flame front follows the averaged $\mathrm{OH}$ concentration maps. Thus, the flame fronts may be individuated mainly into the aforementioned two regions: one within the IRZ and the second one on the inner shear layer. Furthermore, at lower values of $\lambda$ traces of flame fronts presence can be individuated in correspondence of the external shear layer, at the interface between the swirling jet and the outer flow field. None the less, such a presence of flame fronts appears quite weak and almost negligible, where the $\mathrm{OH}$ concentration in the same location appears quite more relevant. This allows considering that the outer shear layer (for lower global air to fuel ratios) is interested more by a protracting $\mathrm{OH}$ kinetic, elsewhere incepted, than by an independent combustion inception (though weakly witnessed).

The average flame front distributions have been successively post processed in order to individuate the local maxima as a function of the axial coordinate (independently within the two main flame fronts locations: within the IRZ and on the inner shear layer). This allowed finding two lines (depicted in red in Fig. 11) representing the Most Probable Location (MPL) of flame fronts (one for each of the two main reaction zone) for each operating condition. In fact, the flame fronts in a single snapshot are represented by a binarization of the greyscale image. As a consequence, the mean distribution of the flame fronts corresponds to a spatial probability density function, where higher pixel values correspond to more flame fronts happened in that specific pixel [51]. 

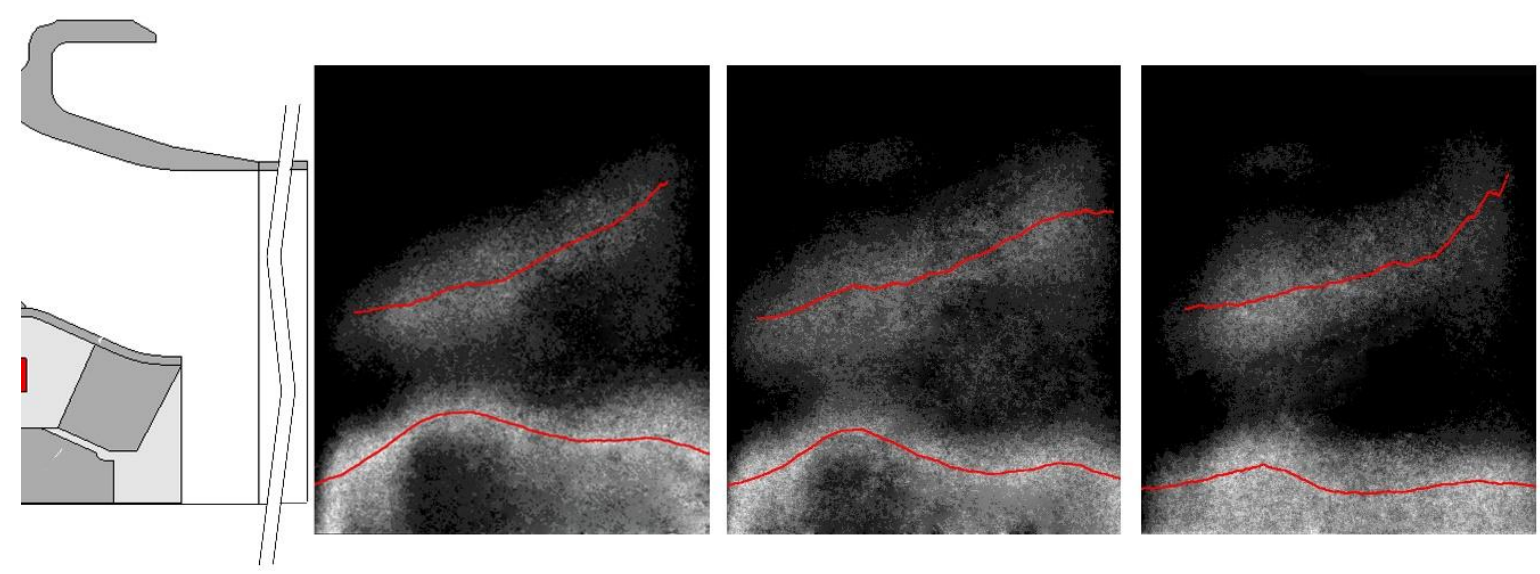

Fig. 11. Flame fronts average location related (from left to right side) to the operating conditions from \#1 to \#3 - The red line shows the most probable position of the flame fronts placed both within the IRZ and at the inner shear layer.

In Figure 11, the average flame fronts distributions, for the three operating conditions, are depicted positioned downstream the burner (sketched) outlet. It can be noticed that the average siting of the flame front follows the averaged $\mathrm{OH}$ concentration maps. Thus, two main regions where fronts mainly can be found are individuated: one within the IRZ, the second one on the inner shear layer. Furthermore, at lower values of $\lambda$ traces of flame fronts presence can be individuated in correspondence of the external shear layer, at the interface between the swirling jet and the outer motionless flow field. None the less, this external presence of flame fronts appears quite weak and almost negligible, where the $\mathrm{OH}$ concentration in the same location appears quite more relevant. This allow considering that the outer shear layer (for lower global air to fuel ratios) is interested more by a protracting $\mathrm{OH}$ kinetic, elsewhere incepted, than by an independent combustion inception (though weakly witnessed).

The average flame front distribution maps have been processed in order to individuate the signal local maxima (independently within the two main flame fronts locations: within the IRZ and on the inner shear layer) as a function of the axial coordinate. This allowed finding two lines (depicted in red in Fig. 11) representing the Most Probable Location (MPL) of flame fronts for each operating condition.

Reporting the MPL lines on Cartesian diagrams (Figure 12) allows observing a different behaviour of the two reaction zones. Whilst the location of flame fronts on the shear layer appears to be independent on the global air to fuel ratio, the MPL of flame fronts within the IRZ progressively moves towards inner radii for decreasing $\lambda$.
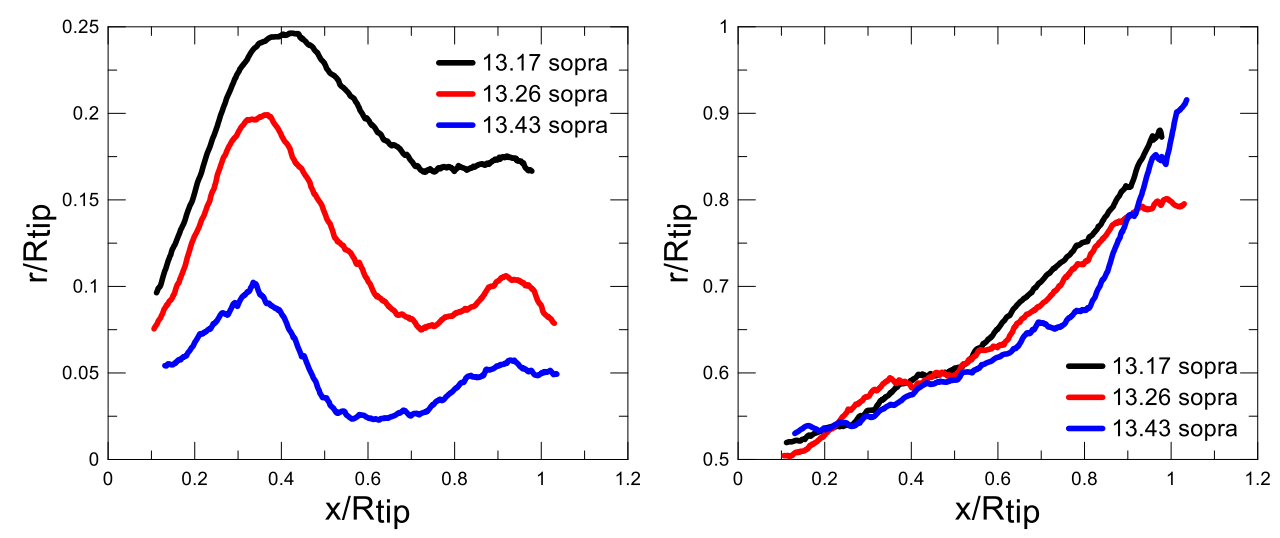

Fig. 12. Most probable location of flame fronts within the IRZ (left) and on the inner shear layer (right).

In addition, it can be observed (Figure 11) that in the region within the IRZ and for $x / R_{\text {out }}$ ranging from 0.1 to 0.5 a flame front free nucleus can be observed for operating condition \#1. As $\lambda$ decreases, 
the probability of having flame fronts also within that nucleus grows up to a uniform probability density of flame fronts presence in the volume enclosed within the MPL line for $\lambda=2.90$. This behaviour could suggest that premixed air and fuel together with partially oxidised products brought back towards the burner outlet by the reversed flow within the IRZ more promptly are ignited because of the more intense thermal release and higher temperatures in presence of globally richer combustion.

\section{Conclusions}

The present work presents the results of an experimental campaign aimed at characterising the combustion process due to a prototype of turbogas partially premixed, swirl stabilized burner, fed with a $\mathrm{H}_{2}$ enriched syngas, by means of LIF measurements.

The investigation had the objective of putting in evidence the main average features and behaviours of a flame developing within a motion flow field characterised by a complex aerodynamics. A post-processing algorithm has been applied to the LIF signal allowing the individuation of the flame fronts individuation.

A statistical analysis of the data made possible bringing into light stable features, i.e. independent on the global air to fuel ratio variation, of the observed combustive phenomenon and other showing a behaviour influenced by that parameter.

As the data acquisitions have not been triggered with signals generated by periodical phenomena potentially taking place within the test section, as typically is observed downstream a swirl stabilized burner, no time dependant analysis of the combustive phenomena have been carried out within the frame of the present work.

This is the object of an ongoing deepening of the experimental activity carried out on the here studied that will be the object of further works for next future.

\section{References}

1. Klimstra J. Interchangeability of gaseous fuels the importance of the Wobbe-index. SAE Trans 1986;95:962e72. doi: 10.4271/861578.

2. A.K. Rajvanshi , Biomass Gasification, Alternative Energy in Agriculture Vol. II, CRC Press, 1986, pp. 83102. doi: 10.1016/j.egypro.2014.07.082.

3. J. Natarajan, T. Lieuwen, J. Seitzman, Laminar flame speeds of $\mathrm{H} 2$ /CO mixtures: effect of CO 2 dilution, preheat temperature, and pressure, Combust. Flame 151 (2007) 104-119. doi: 10.1115/GT2008-51364.

4. C. Dong, Q. Zhou, Q. Zhao, Y. Zhang, T. Xu , S. Hui , Experimental study on the laminar flame speed of hydrogen/carbon monoxide/air mixtures, Fuel 88 (10) (2009) 1858-1863. doi: 10.1016/j.fuel.2009.04.024.

5. A. Keromones , W.K. Metcalfe, K.A. Heufer, N. Donohoe, A.K. Das , C.J. Sung , J. Herzler , C. Naumann, P. Griebel , O. Mathieu, M.C. Krejci , E.L. Petersen, W.J. Pitz , H.J. Curran, An experimental and detailed chemical kinetic modeling study of hydrogen and syngas mixture oxidation at elevated pressures, Combust. Flame 160 (2013) 995-1011. doi: 10.1016/j.combustflame.2013.01.001.

6. M.C. Krejci , O. Mathieu , A.J. Vissotski, S. Ravi , T.G. Sikes , E.L. Peterson, A. Keromones, W. Metcalfe , H.J. Curran, Laminar flame speed and ignition de- lay time data for the kinetic modeling of hydrogen and syngas fuel blends, ASME. J. Eng. Gas Turbines Power 135 (2013) 021503-021509. doi: 10.1115/1.4007737.

7. A.B. Sahu, R.V. Ravikrishna, Effect of $\mathrm{H} 2 / \mathrm{CO}$ composition on extinction strain rates of counterflow syngas flames, Energy Fuels 29 (2015) 4586-4596.

8. Huang Y, Yang V. Dynamics and stability of lean-premixed swirl-stabilized combustion. Prog Energy Combust Sci 2009; 35:293e364. doi: 10.1016/j.pecs.2009.01.002.

9. Giles, D. E., Som, S., Aggarwal, S. K. NOx emission characteristics of counterflow syngas diffusion flames with airstream dilution, Fuel, 85(12-13), 1729-1742, (2006). doi: 10.1016/j.fuel.2006.01.027.

10. Louis, J. J., Kok, J. B., \& Klein, S. A. (2001). Modeling and measurements of a 16-kW turbulent nonadiabatic syngas diffusion flame in a cooled cylindrical combustion chamber. Combustion and Flame, 125(1-2), 10121031. doi: 10.1016/S0010-2180(01)00223-1.

11. Gran, I. R., \& Magnussen, B. F. (1996). A numerical study of a bluff-body stabilized diffusion flame. Part 1. Influence of turbulence modeling and boundary conditions. Combustion science and technology, 119(1-6), 171-190. doi: 10.1080/00102209608951998. 
12. Natarajan, J., Lieuwen, T., \& Seitzman, J. (2007). Laminar flame speeds of H2/CO mixtures: effect of CO2 dilution, preheat temperature, and pressure. Combustion and flame, 151(1-2), 104-119. doi: 10.1016/j.combustflame.2007.05.003. doi: 10.1016/j.combustflame.2007.05.003.

13. Sahu, A. B., Krishna, S., \& Ravikrishna, R. V. (2017). Quantitative OH measurements and numerical investigation of $\mathrm{H} 2 / \mathrm{CO}$ kinetics in syngas-air counterflow diffusion flames. Fuel, 193, 119-133. doi: 10.1016/j.fuel.2016.12.023. doi: 10.1016/j.fuel.2016.12.023.

14. Fu, J., Tang, C., Jin, W., Thi, L. D., Huang, Z., \& Zhang, Y. (2013). Study on laminar flame speed and flame structure of syngas with varied compositions using OH-PLIF and spectrograph. International journal of hydrogen energy, 38(3), 1636-1643. doi: 10.1016/j.ijhydene.2012.11.023.

15. Daniele, S., Jansohn, P., Mantzaras, J., \& Boulouchos, K. (2011). Turbulent flame speed for syngas at gas turbine relevant conditions. Proceedings of the Combustion Institute, 33(2), 2937-2944. doi: 10.1016/j.proci.2010.05.057.

16. Wang, J., Zhang, M., Huang, Z., Kudo, T., \& Kobayashi, H. (2013). Measurement of the instantaneous flame front structure of syngas turbulent premixed flames at high pressure. Combustion and Flame, 160(11), 2434-2441. doi: 10.1016/j.combustflame.2013.06.008.

17. Daniele, S., Mantzaras, J., Jansohn, P., Denisov, A., \& Boulouchos, K. (2013). Flame front/turbulence interaction for syngas fuels in the thin reaction zones regime: turbulent and stretched laminar flame speeds at elevated pressures and temperatures. Journal of Fluid Mechanics, 724, 36-68. doi: 10.1017/jfm.2013.141.

18. Cheng, R. K., Lieuwen, T., Yang, V., \& Yetter, R. (2009). Turbulent combustion properties of premixed syngas. Synthesis Gas Combustion: Fundamentals and Applications, 403. doi:

19. Boutier, A. Accuracy of Laser Velocimetry. Lecture Series 1991-05, 1991, VKI, Brussels.

20. Strazisar, T., 1986, "Laser Anemometry in Compressors and Turbines," ASME Lecture on Fluid Dynamics of Turbomachinery.

21. Grant, I., 1997, "Particle image velocimetry: a review", Proc. Instn. Mech. Engrs, 211 Part C, pp. 55-76.

22. Prasad, A.K., Adrian, R.J., Landreth, C.C., and Offutt, P.W., 1992, "Effect of resolution on the speed and the accuracy of particle image velocimetry interrogation", Experiments in Fluids, 13, pp. 105-116.

23. Schneider, C.; Dreizler, A.; Janicka, J. Fluid Dynamical Analysis of Atmospheric Reacting and Isothermal Swirling Flows. Flow Turbulence Combust 2005, 74-103. doi:10.1007/s10494-005-7369-z.

24. Habisreuther, P.; Bender, C.; Petsch, O.; Buchner, H.; Bockhorn, H. Prediction of pressure Oscillations in a premixed swirl combustor flow and comparison to measurements. Flow, Turbulence and Combustion, 2006, 77, 147-160. doi:10.1016/B978-008044544-1/50082-0.

25. Canepa, E.; Di Martino, P.; Formosa, P.; Ubaldi, M.; Zunino, P. Unsteady aerodynamics of an aeroengine double swirler lean premixing prevaporizing burner. Journal of engineering for gas turbines and power, 2006, 128.1, 29-39. doi: 10.1115/1.1924720.

26. Canepa, E.; Cattanei, A.; Lengani, D.; Ubaldi, M.; Zunino, P. Experimental investigation of the vortex breakdown in a lean premixing prevaporizing burner. Journal of Fluid Mechanics, 2015, 768. doi: 10.1017/jfm.2015.55.

27. Accornero, D.; Caruggi, M.; Nilberto, A.; Pittaluga, F. Numerical and Experimental Investigations of Combustion Instability Phenomena in Gas Turbine Burners for Heavy Duty and Aero-Engine Applications. Proceedings of ASME 2011 Turbo Expo: Turbine Technical Conference and Exposition. American Society of Mechanical Engineers, 2011. p. 1193-1203. doi: 10.1115/GT2011-46490.

28. Canepa, E.; Di Martino, P.; Lengani, D.; Ubaldi, M.; Zunino, P. Radial Swirlers and Mixing Tube Assembly Aerodynamics and Performance Parameters Evaluation: Part 1 - Hot-Wire Measurements in the Swirler Exit Plane. Proceedings of ASME Turbo Expo 2008: Power for Land, Sea, and Air. American Society of Mechanical Engineers, 2008. p. 931-940. doi: 10.1115/GT2008-51213.

29. Canepa, E.; Di Martino, P.; Lengani, D.; Ubaldi, M.; Zunino, P. Radial Swirlers and Mixing Tube Assembly Aerodynamics and Performance Parameters Evaluation: Part 2 - LDV Measurements at the Mixing Tube Outlet. Proceedings of ASME Turbo Expo 2008: Power for Land, Sea, and Air. American Society of Mechanical Engineers, 2008. p. 941-950. doi: 10.1115/GT2008-51221.

30. Mallard, E.; Le Chatelier, H.L. Annales de Mines. 4th ed., 1883, p. 379.

31. Zeldovich, Y.B.; Frank-Kamenetsky, D.A. The theory of thermal propagation of flames. Acta Phisicochim., 1938, 9, 341.

32. Glassman, I. Combustion, 3rd ed.; Academic Press: Cambrodge, Massachussets, USA, 1996, ISBN 9780080529417. 
33. Williams, F. A. Combustion Theory, 2nd ed., The Benjamin/Cummings Publishing Company: Menlo Park, California, USA, 1985, ISBN 0-8053-9801-5.

34. Warnatz, J. The Structure of Laminar Alkane-, Alkene-, and Acetylene Flames. Eighteen Symposium (International) on Combustion, the Combustion Institute, University of Waterloo, Waterloo, Canada, 17-22 August 1980, Elsevier Inc., pp. 369-384, ISSN 0082-0784.

35. Guethe, F.; Lachner, R.; Schuermans, B.; Biagioli, F.; Geng, W.; Inauen, A.; Schenker, S.; Bombach, R.; Tylli, T.; Hubschmid, W. Flame imaging on the ALSTOM EV-burner: thermo acoustic pulsations and CFDvalidation. 44th AIAA Aerospace Sciences Meeting and Exhibit., Reno, Nevada, USA, 2006, doi:10.2514/6.2006-437

36. Hult, J.; Josefsson, G.; Alde'n, M.; Kaminski, C. F. Flame front tracking and simultaneous flow field visualisation in turbulent combustion. 10th International Symposium on Applications of Laser Techniques to Fluid Mechanics, Lisbon, Portugal, 10-13 July 2000.

37. Troiani, G.; Marrocco, M.; Imaging of Flame Fronts by Fluorescence of Hydroxyl Radicals: a Fractal Approach for the Determination of Front Position. XXXIV Meeting of the Italian Section of the Combustion Institute, Rome, Italy, 2011, doi:10.2514/MASM06

38. Hubschmid, W.; Bombach, R.; Inauen, A.; Güthe, F.; Schenker, S.; Tylli, N.; Kreutner, W. Thermoacoustically driven flame motion and heat release variation in a swirl-stabilized gas turbine burner investigated by LIF and chemiluminescence. Experiments in Fluids, 2008, 45, 167-182. doi:10.1007/s00348008-0497-1.

39. Sadanandan, R.; Stöhr, M.; \& Meier, W. Simultaneous OH-PLIF and PIV measurements in a gas turbine model combustor. Applied Physics B, 2008, 90(3-4), 609-618. doi:10.1007/s00340-007-2928-8.

40. Meier, W.; Boxx, I.; Stöhr, M.; Carter, C. D. Laser-based investigations in gas turbine model combustors. Experiments in Fluids, 2010, 49(4), 865-882. doi:10.1007/s00348-010-0889-x.

41. Bayley, A. E.; Hardalupas, Y.; Taylor, A. M. K. P. Local Curvature Measurements of a Lean, Partially Premixed Swirl-stabilised Flame. Experiments in Fluids, 2012, 52, 963-983. doi:10.1007/s00348-011-1181-4.

42. Scharr, H.; Jähne, B.; Böckle, S.; Kazenwadel, J.; Kunzelmann, T.; Schulz, C. Flame Front Analysis in Turbulent Combustion. In: Sommer G., Krüger N., Perwass C. (eds) Mustererkennung 2000. Informatik aktuell. Springer, Berlin, Heidelberg. doi:10.1007/978-3-642-59802-9_41.

43. Daniele, S.; Jansohn, P.; Boulouchos, K. Flame Front Characteristic and Turbulent Flame Speed of Lean Premixed Syngas Combustion at Gas Turbine Relevant Conditions. Proceedings of ASME Turbo Expo 2009: Power for Land, Sea and Air GT2009, Orlando, Florida, USA, 8-12 June 2009, pp. 393-400. doi: 10.1115/GT2009-59477.

44. Hartung, G.; Hult, J.; Balachandran, R.; Mackley, M. R.; Kaminski, C. F. Flame front tracking in turbulent lean premixed flames using stereo PIV and time-sequenced planar LIF of OH. Applied Physics B, 2009, 96(4), 843-862. doi:10.1007/s00340-009-3647-0.

45. Griebel, P.; Siewert, P.; Jansohn, P. Flame characteristics of turbulent lean premixed methane/air flames at high pressure: Turbulent flame speed and flame brush thickness. Proceedings of the Combustion Institute 31(2), 2007, 3083-3090. doi:10.1016/j.proci.2006.07.042.

46. Perona, P.; Malik, J. Scale-space and Edge Detection Using Anisotropic Diffusion. IEEE Transactions on Pattern Analysis and Machine Intelligence, 1990, 12, 629 - 639. doi:10.1109/34.56205.

47. Weickert, J.; Romeny, B. M. T. H.; Viergever, M. A. Efficient and Reliable Schemes for Nonlinear Diffusion Filtering, IEEE Trans Image Process, 1998, 7(3), 398-410. doi:10.1109/83.661190.

48. Malm, H.; Sparr, G.; Hult, J.; Kaminski, C. Nonlinear diffusion filtering of images obtained by planar laserinduced fluorescence spectroscopy. Journal of the Optical Society of America, 2001, 17(12), 2148-56. doi:10.1364/JOSAA.17.002148.

49. Schießl, R.; Dreizler, A.; Maas, U. Comparison of Different Ways for Image Post-Processing: Detection of Flame Fronts, International Fuels \& Lubricants Meeting \& Exposition, SAE Technical Paper 1999-01-3651, 1999. doi:10.4271/1999-01-3651.

50. Gonzalez, R. C.; Woods, R. E. Digital Image Processing, 2nd ed., Prentice-Hall: Upper Saddle River, New Jersey, USA, 2002.

51. Siewert, P. Flame front characteristic of turbulent lean premixed methane/air flames at high-pressure. Doctoral thesis, ETH, Zurich, 2006. 